\title{
Extragenital lichen sclerosus of the breast and silicone breast implants
}

\author{
Alberto Goldman ${ }^{1}$, Uwe Wollina² \\ ${ }^{1}$ Department of Plastic Surgery, Hospital São Lucas da PUCS, Porto Alegre, Brazil, ${ }^{2}$ Department of Dermatology and \\ Allergology, Städtisches Klinikum Dresden, Dresden, Germany \\ Corresponding author: Prof. Uwe Wollina, MD PhD, E-mail: Uwe.Wollina@klinikum-dresden.de
}

\begin{abstract}
Lichen sclerosus of the breast (LSB) is an uncommon inflammatory dermatosis of an incompletely understood pathogenesis. Herein, we report the case of a 29-year-old female who developed LSB 23 years after a silicone breast implant. A diagnostic skin biopsy revealed the typical three-layered pathology of an atrophic epidermis with the loss of rete ridges and basal keratinocyte vacuolization, a subepidermal band of sclerosis, and a lichenoid infiltrate of lymphocytes beneath that band. We discuss the possible relationship between silicone breast implants and autoimmune disorders.
\end{abstract}

Keywords: Silicone breast implant; Lichen sclerosus; Breast; Histopathology; Autoimmune disorders

\section{INTRODUCTION}

Lichen sclerosus atrophicus (LSA) is a chronic inflammatory disorder with a clear predominance of females. The prevalence of LSA is $0.1 \%$ in children and $3 \%$ in females older than eighty years. Any skin site may be affected by the disease, but LSA is most common in the anogenital area, where it causes intractable itching and soreness [1].

The cause of LSA is poorly understood. Oxidative stress, autoimmune features such as autoantibodies against extracellular matrix protein 1 and BP180 antigen, and increased Thl activity are considered contributing factors [2].

Extragenital LSA has been reported in $6 \%$ to $20 \%$ of cases. The typical clinical symptoms of extragenital LSA are pale, ivory-colored plaques with an atrophic, cellophane, paper-like epidermis. This may be accompanied by purpura or ecchymosis, fissures, sclerosis, and rarely blisters. Pruritus is less common and, if present, is milder than in anogenital LSA.
Histopathology of LSA is characterized by a threelayer pathology that consists of an atrophic epidermis with the loss of rete ridges and basal keratinocyte vacuolization, a subepidermal band of sclerosis, and a lichenoid infiltrate of lymphocytes beneath that band. The upper dermis may be present with edema to a variable degree. Follicular plugging may be observed [3].

\section{CASE REPORT}

An otherwise healthy 29-year-old female had a reduction mammoplasty in 1991. In 2014-23 years after the primary procedure-she had the second mammoplasty with a silicone breast implant, which was implanted by the inframammary approach using the previous scar. No problems were noted during the surgery as well as during the post-op period (Fig. 1).

Two years later, the patient returned with a skin lesion on the left breast. A whitish pale plaque with an atrophic epidermis could be clearly seen (Fig. 2). A skin biopsy was taken, which confirmed extragenital LSA (Fig. 3). 


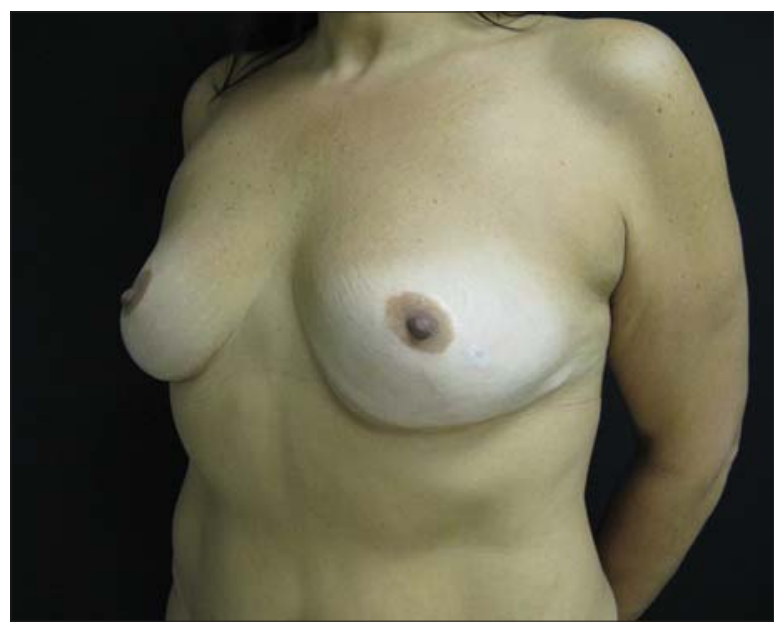

Figure 1: Whitish plaque seen paramammillarily on the left breast.

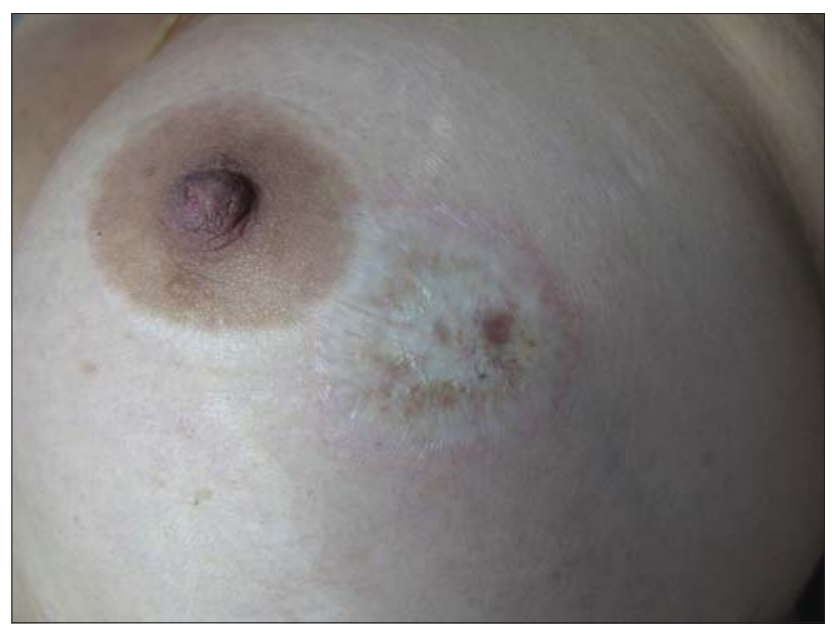

Figure 2: Enlarged whitish plaque with an atrophic epidermis (extragenital LSA).

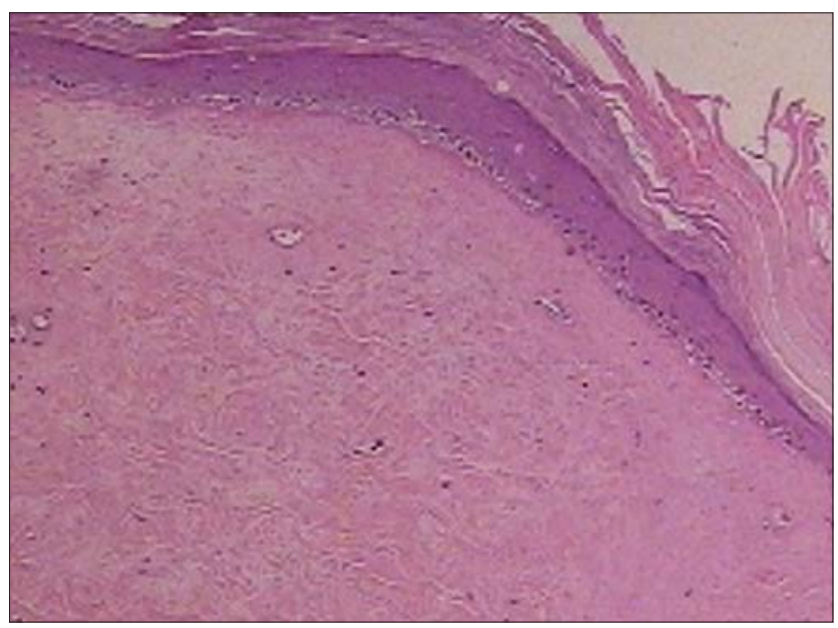

Figure 3: Histopathology of extragenital LSA; loss of rete ridges, basal keratinocyte vacuolization, band-like sclerosis, and a mild lymphocytic infiltrate.

Topical treatment with corticosteroid ointment was recommended.

\section{DISCUSSION}

LSA of the breast is less common. It has been reported after radiotherapy for breast cancer [4-6]. However, in the present case, there was no history of breast cancer or radiotherapy.

In the past decades, there has been a discussion on connective tissue disorders and silicone breast implants. There are some case reports on morphea after a breast implant [7]. In a large cohort study on more than 85,000 female patients; however, no increased risk for the development of connective tissue disease by silicone breast implants was confirmed [8].

An analysis of 24,651 silicone breast implant patients and 98,604 matched females without silicone implants found an adjusted odds ratio between implants and being diagnosed with any autoimmune or rheumatic disorder of 1.22 (95\%; CI: 1.18-1.26) and a hazard ratio of 1.45 (95\%; CI: 1.21-1.73). Disorders with an OR of more than 1.5 were Sjögren's syndrome, systemic scleroderma, and sarcoidosis [9].

This has not been reported for silicone breast implants and LSA. Therefore, we assume that the development of extragenital LSA in our patients was unrelated to the surgical procedures.

\section{CONSENT}

The examination of the patient was conducted according to the principles of the Declaration of Helsinki.

The authors certify that they have obtained all appropriate patient consent forms, in which the patients gave their consent for images and other clinical information to be included in the journal. The patients understand that their names and initials will not be published and due effort will be made to conceal their identity, but that anonymity cannot be guaranteed.

\section{REFERENCES}

1. Powell JJ, Wojnarowska F. Lichen sclerosus. Lancet. 1999;353: 1777-83.

2. Kirtschig G. Lichen sclerosus - Presentation, diagnosis and management. Dtsch Arztebl Int. 2016;113:337-43.

3. Dalal V, Kaur M, Rai CB, Singh A, Ramesh V. Histopathological spectrum of lichen sclerosus et atrophicus. Indian J Dermatopathol Diagn Dermatol. 2017;4:8-13.

4. Bonfill-Ortí M, Martínez-Molina L, Penín RM, Marcoval J. Extragenital lichen sclerosus induced by radiotherapy. Actas Dermosifiliogr. 2019;110:69-71.

5. Nemer KM, Anadkat MJ. Postirradiation lichen sclerosus et 


\section{www.odermatol.com}

atrophicus. JAMA Dermatol. 2017;153:1067-9.

6. Moore KA, Potter JE. Lichen sclerosus in a breast cancer survivor. J Gen Intern Med. 2013;28:345.

7. Moretti A, Bianchi F, Abbate IV, Gherardi G, Bonavita M, Passoni E, et al. Localized morphea after breast implant for breast cancer: A case report. Tumori. 2018;104:NP25-8.

8. Sánchez-Guerrero J, Colditz GA, Karlson EW, Hunter DJ, Speizer FE, Liang MH. Silicone breast implants and the risk of connective-tissue diseases and symptoms. N Engl J Med. 1995;332:1666-70.
9. Watad A, Rosenberg V, Tiosano S, Cohen Tervaert JW, Yavne Y, Shoenfeld Y, et al. Silicone breast implants and the risk of autoimmune/rheumatic disorders: A real-world analysis. Int J Epidemiol. 2018;47:1846-54.

Copyright by Alberto Goldman, et al. This is an open access article distributed under the terms of the Creative Commons Attribution License, which permits unrestricted use, distribution, and reproduction in any medium, provided the original author and source are credited. Source of Support: Nil, Conflict of Interest: None declared. 